\title{
Robust STABILIZATION OF A HeATING-COOLING SySTEM BY USING TwO FEEDBACK CONTROLLERS: A NUMERICAL- GRAPHICAL ANALYSIS
}

\author{
Radek Matušů, Libor Pekař \& Jiří Korbel
}
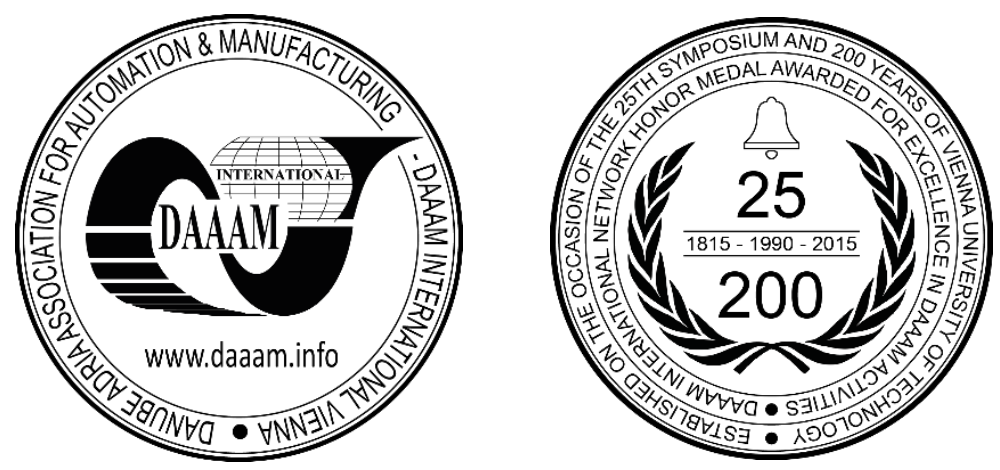

This Publication has to be referred as: Matusu, R[adek]; Pekar, L[ibor] \& Korbel, J[iri] (2017). Robust Stabilization of a Heating-Cooling System by Using Two Feedback Controllers: a Numerical-Graphical Analysis, Proceedings of the 28th DAAAM International Symposium, pp.0194-0198, B. Katalinic (Ed.), Published by DAAAM International, ISBN 978-3-902734-11-2, ISSN 1726-9679, Vienna, Austria

DOI: $10.2507 / 28$ th.daaam.proceedings.026

\begin{abstract}
This contribution is intended to present a numerical-graphical method for analyzing the robust stability of a control loop which contains two feedback controllers and a heating-cooling system with a heat exchanger. The controlled plant is described by the anisochronic model with internal delays and the parameters of this model are supposed to vary within given intervals. The applied technique for robust stability analysis is based on the numerical calculations of the value sets in combination with the graphical test via the zero exclusion condition.
\end{abstract}

Keywords: Robust Stability; Parametric Uncertainty; Anisochronic Model; Heating-Cooling System; Heat Exchanger; Two Feedback Controllers

\section{Introduction}

Robust stability is the key property of the control systems under uncertainty and its analysis has attracted the researchers for several decades [1], [2], [3], [4]. Generally, the more complicated type and structure of uncertainty is presented in the model, the more sophisticated and complex tools have to be used for testing the robust stability. However, the value set concept combined with the zero exclusion condition [1] represents extremely universal technique which can be applied to various ranges of parametric uncertainty structures [5], [6].

In this contribution, the robust stability of a control loop with two feedback controllers and a heating-cooling system with a heat exchanger [7], modelled as the anisochronic model with internal delays and parametric uncertainty, is analyzed with the assistance of the numerical calculations of the value sets and the graphical evaluation of the zero exclusion condition. The paper presents the modified version of the example that has been already published in the previous work [6]. 


\section{Process Description}

Assume a cooling-heating system with a through-flow air-water heat exchanger that evinces long internal delays. In [7], [8], the plant was modelled by means of the anisochronic principle - see e.g. [9]. This approach allowed including all significant delays and latencies caused by the heat transferring from a source through a piping system by using the heat transferring media (water) into a heat-consuming part.

The process was described in [7], [8] by a set of ordinary differential equations and algebraic equations. Subsequently, the same works [7], [8] derived also a linearized model formulated by the transfer function:

$$
G(s)=\frac{\left(b_{0}+b_{0 D} e^{-\Theta_{0} s}\right) e^{-\Theta_{b} s}}{s^{3}+a_{2} s^{2}+a_{1} s+a_{0}+a_{0 D} e^{-\Theta_{a} s}}
$$

which expresses the relation between the input power to the heater and the outlet stream temperature from the heat exchanger.

The nominal parameters identified in the specific operating point are [7]:

$$
\begin{aligned}
& b_{0}=-2.052 \times 10^{-7} \\
& b_{0 D}=2.334 \times 10^{-6} \\
& \Theta_{0}=1.5 \\
& \Theta_{0 b}=141 \\
& a_{2}=0.1767 \\
& a_{1}=0.08989 \\
& a_{0}=1.413 \times 10^{-4} \\
& a_{0 D}=-7.625 \times 10^{-5} \\
& \Theta_{0 a}=151
\end{aligned}
$$

The experiments in [7] showed that the plant is affected by the parameter perturbations and other non-modelled internal and external influences.

The robust stability test from [6] supposed the possible variations of the size $\pm 10 \%$ of all the nominal parameter values (2). In this contribution, the robust stability is analyzed for the variations of the size $\pm 15 \%$, i.e.:

$$
\begin{aligned}
& b_{0} \in\left[-2.3598 \times 10^{-7},-1.7442 \times 10^{-7}\right] \\
& b_{0 D} \in\left[1.9839 \times 10^{-6}, 2.6841 \times 10^{-6}\right] \\
& \Theta_{0} \in[1.275,1.725] \\
& \Theta_{0 b} \in[119.85,162.15] \\
& a_{2} \in[0.150195,0.203205] \\
& a_{1} \in[0.0764065,0.1033735] \\
& a_{0} \in\left[1.20105 \times 10^{-4}, 1.62495 \times 10^{-4}\right] \\
& a_{0 D} \in\left[-8.76875 \times 10^{-5},-6.48125 \times 10^{-5}\right] \\
& \Theta_{0 a} \in[128.35,173.65]
\end{aligned}
$$

\section{Control Loop}

The control system with two feedback controllers was chosen as a convenient configuration. The scheme of this control loop is shown in Fig. 1. Two feedback controllers are represented by the blocks $C_{R}$ and $C_{Q}$ and a controlled plant by the block $G$.

The signals are denoted as follows: $w$ - reference signal, $e$ - tracking (control) error, $u_{0}$ - difference of controllers' outputs, $u$-control signal, $y$-controlled signal (output), $v$ - load disturbance. 


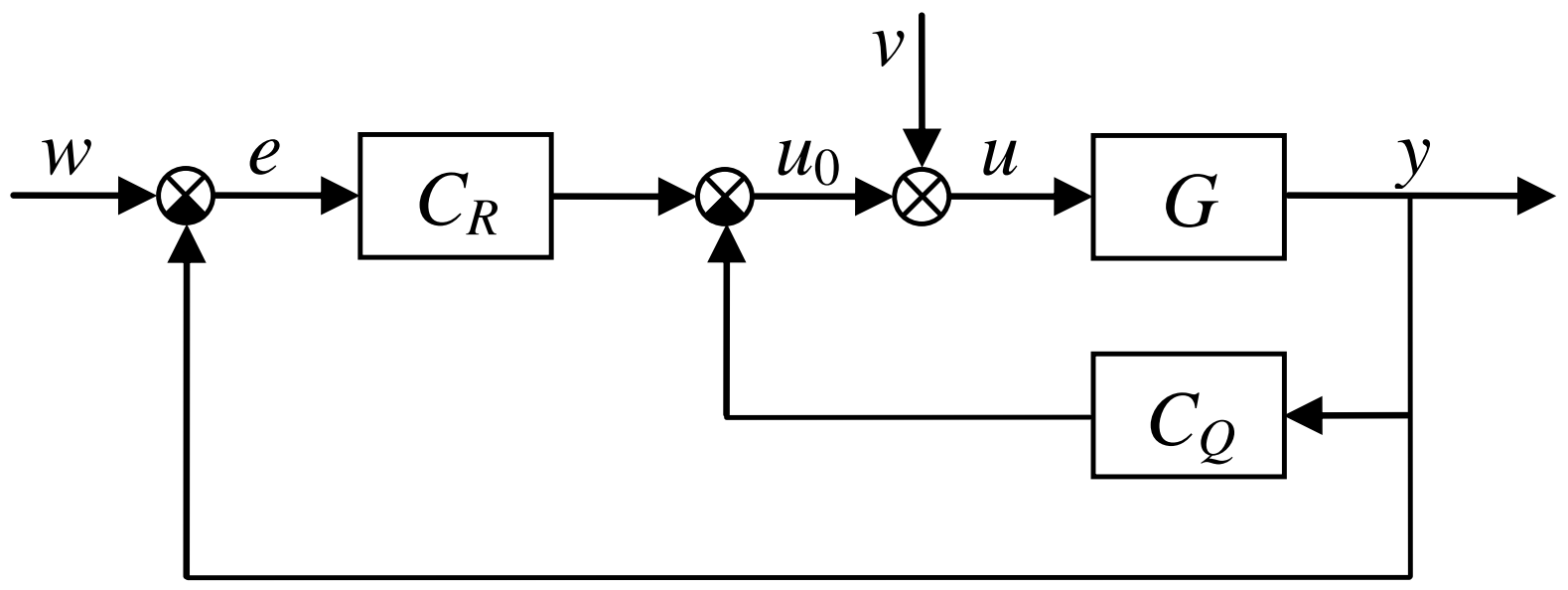

Fig. 1. Control loop with two feedback controllers

In [7], [8], the controllers:

$$
\begin{aligned}
& C_{R}(s)=\frac{47.2676 s^{2}+0.416887 s+6.16545 \times 10^{-4}}{s^{2}} \\
& C_{Q}(s)=24.6114
\end{aligned}
$$

were designed via the algebraic method for the system (1) with nominal parameters (2).

\section{Robust Stability Analysis}

Remind that the aim is to analyze the robust stability of the control loop that contains feedback controllers (4) and the heating-cooling system (1) with the uncertain parameters (3). The family of the closed-loop characteristic retarded quasipolynomials is:

$$
\begin{aligned}
& p_{C L}\left(s, b_{0}, b_{0 D}, \Theta_{0}, \Theta_{b}, a_{2}, a_{1}, a_{0}, a_{0 D}, \Theta_{a}\right)=s^{3}+a_{2} s^{2}+a_{1} s+a_{0}+a_{0 D} e^{-\Theta_{a} s}+\cdots \\
& +b_{0} e^{-\Theta_{b} s}\left(47.2676 s^{2}+0.416887 s+24.612016545\right)+b_{0 D} e^{-\left(\Theta_{0}+\Theta_{b}\right) s}\left(47.2676 s^{2}+0.416887 s+24.612016545\right)
\end{aligned}
$$

where all 9 uncertain parameters can vary within the intervals from (3).

The robust stability of this family with quite complicated uncertainty structure will be investigated by means of the value set concept and the zero exclusion condition [1]. Its application to various types of thermal systems with uncertain parameters can be found in [6].

The value sets are obtained numerically through sampling (gridding) the uncertain parameters and subsequent direct calculation of related partial points of the value sets for a suitable pre-selected set of non-negative frequencies. Then, the robust stability is tested graphically - the family is robustly stable if and only if the zero point is excluded from the value sets and all required preconditions are fulfilled, especially the existence of at least one stable member of the family. For details see e.g. [1], [5], [6].

The value sets of the family (5) with the uncertain parameters (3) are plotted in Fig. 2. The value sets are obtained for the frequencies from 0 to 0.5 with the step 0.01 . For the calculations, 7 out of 9 uncertain parameters are sampled by 3 equidistant values and the remaining 2 parameters are sampled by 15 values which mean that the value set consists of $3^{7} \cdot 15^{2}=492075$ points at each frequency.

A closer look near the complex plane origin is depicted in Fig. 3. The family (5) contains a stable member and the zero point is excluded from the value sets which means (with necessary and sufficient condition) that the family is robustly stable, i.e. two feedback controllers (4) stabilize the anisochronic model (1) of a heating-cooling plant for all possible assumed variations of the uncertain parameters (3). 


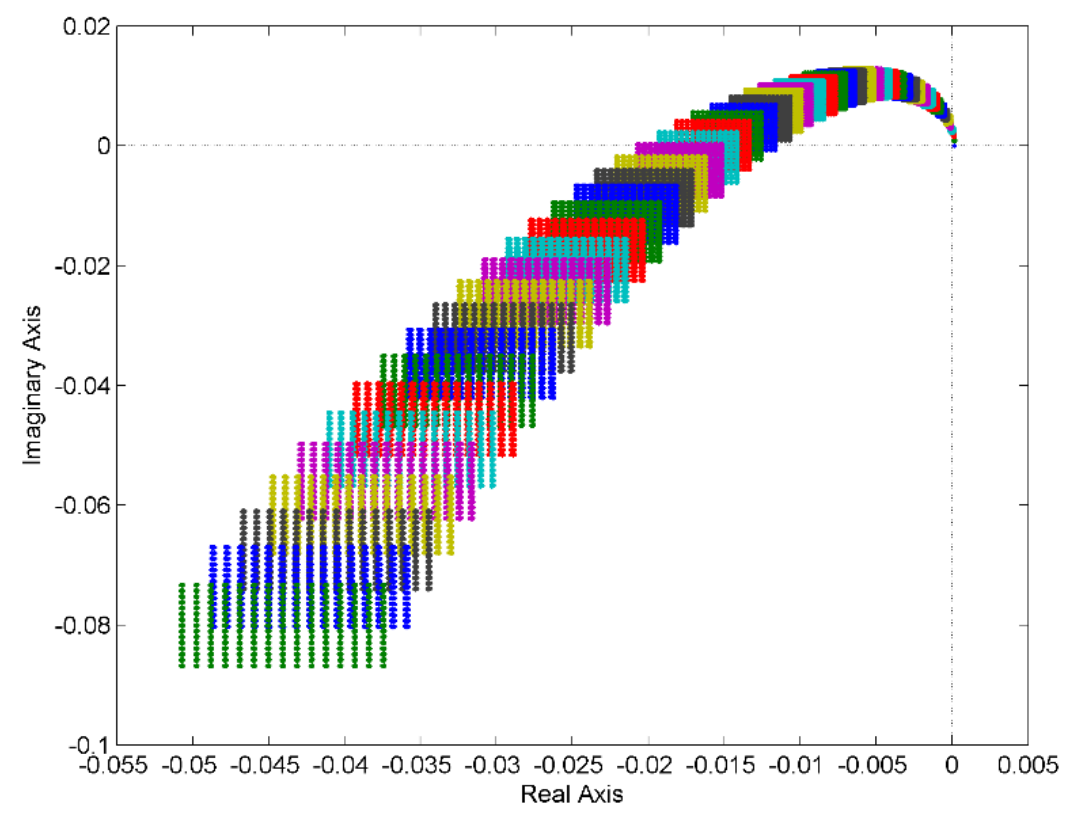

Fig. 2. The value sets of the family (5) with parameters (3) - the full view

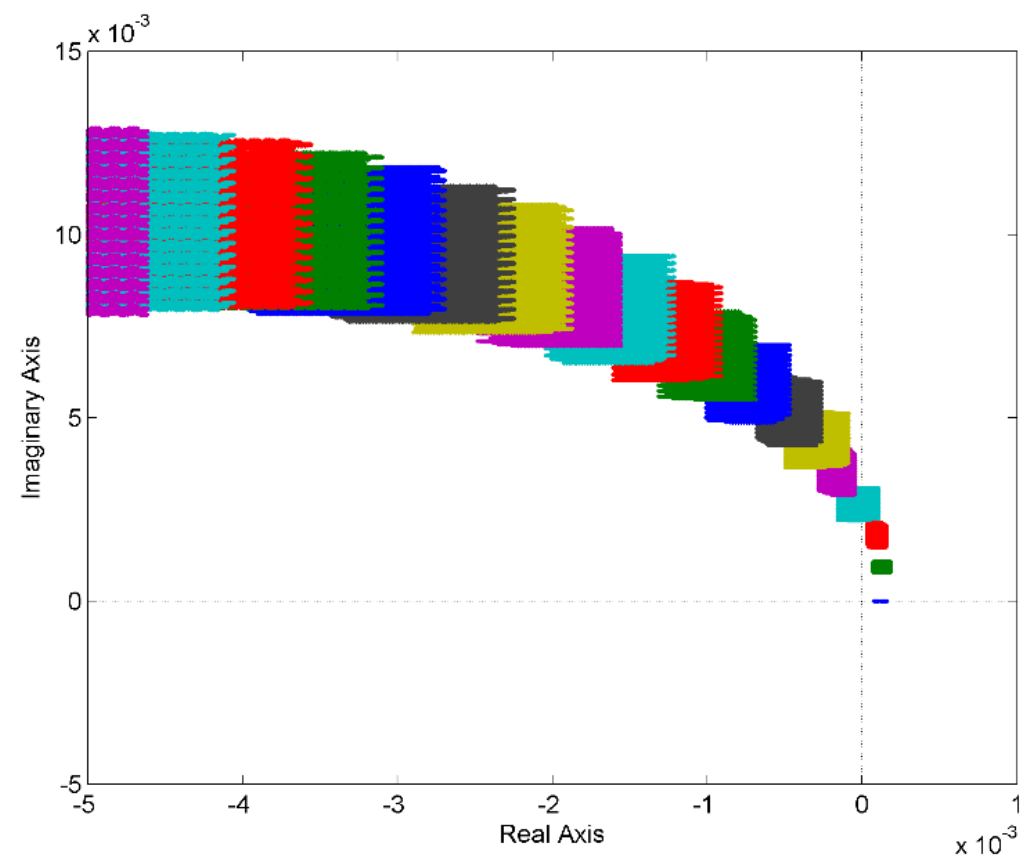

Fig. 3. The value sets of the family (5) with parameters (3) - a zoomed view

\section{Conclusion}

This brief contribution was focused on the numerical-graphical technique for testing the robust stability of the control system with two feedback controllers and the specific thermal plant. The controlled process is represented by a heatingcooling system with a heat exchanger that is described by the anisochronic model with internal delays and parametric uncertainty. The robust stability is analyzed by means of the numerical calculations of the value sets in combination with the graphical evaluation via the zero exclusion condition.

\section{Acknowledgments}

This work was supported by the Ministry of Education, Youth and Sports of the Czech Republic within the National Sustainability Programme project No. LO1303 (MSMT-7778/2014) and also by the European Regional Development Fund under the project CEBIA-Tech No. CZ.1.05/2.1.00/03.0089. 


\section{References}

[1] Barmish, B. R. (1994). New Tools for Robustness of Linear Systems, Macmillan, New York, USA

[2] Bhattacharyya, S. P.; Chapellat, H. \& Keel, L. H. (1995). Robust Control: The Parametric Approach, Prentice Hall, Englewood Cliffs, New Jersey, USA

[3] Bhattacharyya, S. P. (2017). Robust control under parametric uncertainty: An overview and recent results, Annual Reviews in Control, In Press - Corrected Proof, https://doi.org/10.1016/j.arcontrol.2017.05.001

[4] Stevanović, S.; Kasać, J. \& Stepanić, J. (2012). Robust Tracking Control of a Quadrotor Helicopter without Velocity Measurement, Annals of DAAAM for 2012 \& Proceedings of the 23rd International DAAAM Symposium, Vienna, Austria, ISBN 978-3-901509-91-9, ISSN 2304-1382, pp. 595-600

[5] Matušů, R. (2016). Investigation of Robust Stability for Discrete-Time Polynomials with Nonlinear Uncertainty Structure, Proceedings of 27th DAAAM International Symposium, Vienna, Austria, ISBN 978-3-902734-08-2, ISSN 1726-9679, pp. 142-146

[6] Matušů, R. \& Pekař, L. (2017). Robust Stability of Thermal Control Systems with Uncertain Parameters: The Graphical Analysis Examples. Applied Thermal Engineering, Vol. 125, pp. 1157-1163

[7] Pekař, L. \& Prokop, R. (2017). Algebraic robust control of a closed circuit heating-cooling system with a heat exchanger and internal loop delays. Applied Thermal Engineering, Vol. 113, pp. 1464-1474

[8] Pekař, L. (2013). Control of Time Delay Systems - An Algebraic Approach, English Doctoral Thesis, Faculty of Applied Informatics, Tomas Bata University in Zlín, Czech Republic

[9] Zítek, P. \& Hlava, J. (2001). Anisochronic internal model control of time-delay systems. Control Engineering Practice, Vol. 9, No. 5, pp. 501-516 